\title{
Integrated HVAC Management and Optimal Scheduling of Smart Appliances for Community Peak Load Reduction
}

\author{
Krystian X. Perez, Michael Baldea, Thomas F. Edgar* \\ McKetta Department of Chemical Engineering, The University of Texas at Austin, 1 \\ University Station C0400, Austin, TX 78712
}

\begin{abstract}
Of the total electricity-generating capacity in the United States, $20 \%$ is dedicated to meet peak loads. Strategies to mitigate volatility in energy consumption have the potential to reduce the need for this surplus capacity. Here we investigate the potential for residential consumers to lower community-level peak demand through home energy management systems. We focus on the combination of air-conditioning use with the operation of time-shiftable appliances in the southern U.S. A centralized model predictive control (MPC) scheme minimizes peak air-conditioning $(\mathrm{A} / \mathrm{C})$ energy use by altering the thermostat set-points in individual homes. We simultaneously schedule the operation of time-shiftable appliances to further reduce the community peak load. The scheduling problem is formulated as a mixed-integer linear program (MILP) aimed at minimizing peak load under constraints that reflect the start times and allowed delays of individual appliances (e.g. dishwashers, washing machines, dryers) in each house. Using sample data collected from residential homes and consumer survey data located in Austin, TX, USA we show that the proposed integrated control and scheduling approach can minimize the peak load for the neighborhood by leveraging the physical differences and individual preferences between houses. On average, our framework is able to reduce the daily peak load for the group of houses by $25.5 \%(18.2 \mathrm{~kW})$ when compared with the load for individually controlled thermostat settings and appliance start times.
\end{abstract}

\footnotetext{
${ }^{*}$ Corresponding author. Tel.:+1 5124713080

Email address: tfedgar@che.utexas.edu (Thomas F. Edgar)
}

Preprint submitted to Energy and Buildings

March 7, 2016

(C) 2016. This manuscript version is made available under the Elsevier user license http://www.elsevier.com/open-access/userlicense/1.0/ 
Keywords: Smart grid, Demand side management, Load leveling, Flexible loads, Controllable loads, Demand Response

2

\section{INTRODUCTION}

The marginal costs of peak loads in the United States are quite high; of the total installed generating capacity, $20 \%$ is dedicated to meet peak loads, which occur only $5 \%$ of the year on average [1]. Residential energy consumption is roughly $20 \%$ of the total U.S. energy use and a disproportionately large contributor to the peak electricity demand problem. For example, in Texas, residential loads account for nearly $50 \%$ of the summer peak demand, driven primarily by air-conditioning (A/C) use [2]. While industrial and commercial energy use varies incrementally, residential power demand may increase by a factor of five between a moderate day in the spring and a hot day in the summer, e.g., the Dallas/Ft.Worth area of Texas [2].

Residential consumers, in the aggregate, are a significant contributor to peak loads, largely owing to the highly periodic nature of their energy consumption. Energy use patterns follow occupancy schedules (e.g. people tend to arrive home around the same time in the afternoon) and outdoor temperatures (which tend to peak around the same time of day). The variations in energy use between houses are due to the differences between consumers, both in terms of physical parameters (e.g. differences in square footage of dwellings, sizes of air conditioning equipment and number of domestic appliances) as well as behavioral differences (thermostat set points, preferred appliance use times). A/C energy use is a significant contributor to the large swing in residential energy consumption and is driven by daily temperature changes and occupancy [3].

Although they represent a smaller load than A/C units, domestic appliances have a compounding effect and can exacerbate the peak-time demand problem [4]. Thus, meaningful reductions in peak demand could potentially be achieved by ensuring that such appliances do not operate during peak time. In comparison, a typical $\mathrm{A} / \mathrm{C}$ unit requires about $2 \mathrm{~kW}$, while a washing machine/dryer requires about $1 \mathrm{~kW}$ and a dishwasher, $600 \mathrm{~W}$. Figure 1 shows the potential for time-shiftable devices to alleviate peak energy loads. The solid red boxes represent the original start times for a dishwasher based on survey data [4]. During peak hours (4-10 p.m.), highlighted by the large blue box, there are a large number of devices operating at overlapping times. 


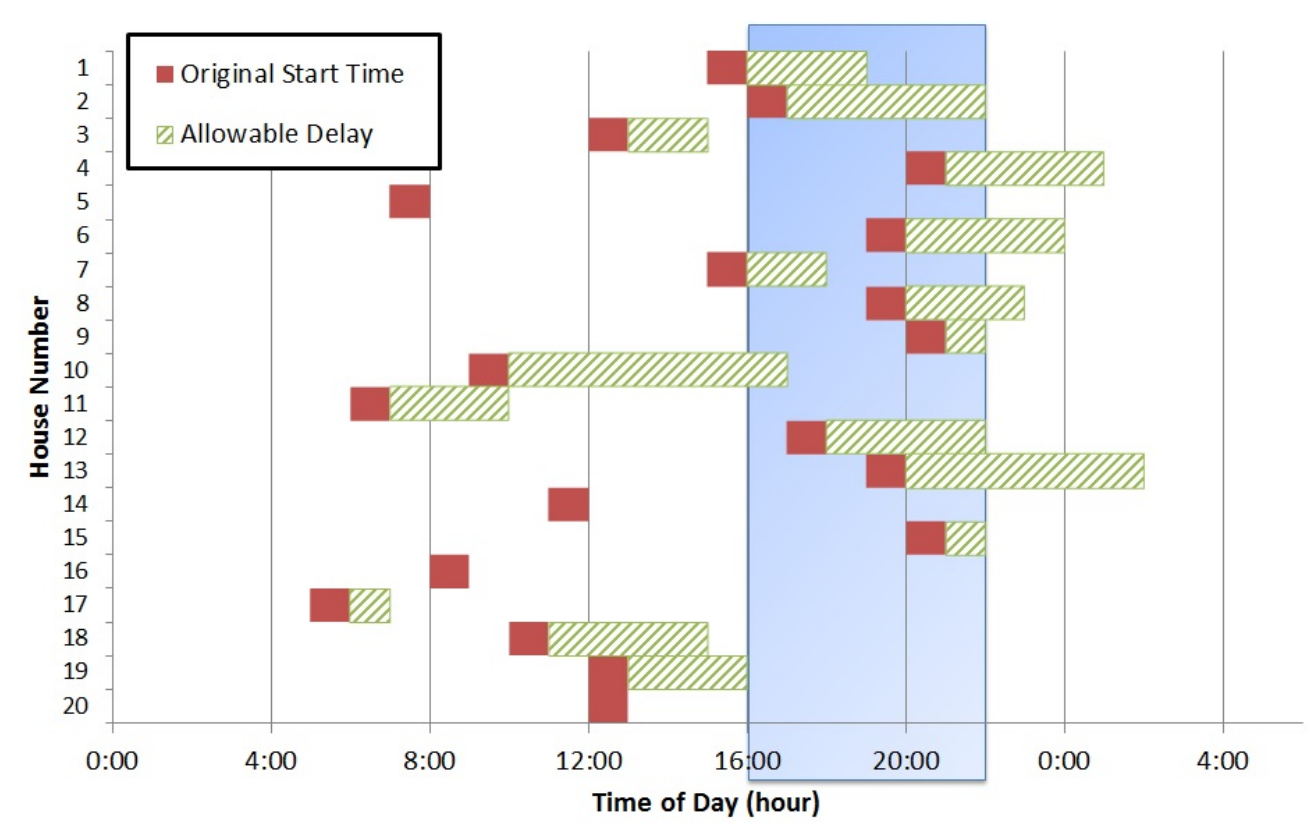

Figure 1: Dishwasher start times (Data from [4]). Solid red boxes represent original userpreferred start-time. Green boxes represent permitted start-time delays. The large blue box represents typical peak periods. The figure represents the potential to shift smart appliance use to lower electricity use during peak periods.

However, if homeowners allow flexibility in completion times (as represented by the extended diagonally-striped green blocks) an ensemble of houses now has the potential to spread out loads or even shift off of peak hours.

One possible avenue to minimize energy use during high-load times is time-of-use (TOU) pricing. Instead of a single, flat energy price for residential consumers, time-of-use pricing schemes involve charging more per $\mathrm{kWh}$ when electricity demand is higher. Energy during on-peak or high energy use hours during the later afternoon is significantly more expensive than off-peak hours late at night. Generally speaking, TOU pricing is useful from a behavioral aspect because it encourages consumers to think about blocks of time as being expensive and incentivizes energy use during other times. Municipalities have found TOU pricing to be useful and some are even offering TOU pricing to residential customers [5]. From a mathematical optimization standpoint, using TOU pricing in peak reduction is troublesome because although it encourages a consumer to require as little energy as possible during on-peak periods, it does not inherently prevent peaking events before (pre-cooling) 
or after on-peak periods and special problem formulations are required to this end. There has been research investigating agent-based TOU pricing for individual users to lower peak loads. In [6], Molderink et. al. found success in lowering peak load by giving tailored TOU prices to energy management systems. However, they admitted that from a human interaction standpoint it may be challenging for users to understand and react to pricing signals without some form of automation. It may be more appropriate to encourage users to achieve certain characteristics such as flattened loads instead such as was shown by Gerards et al. in [7] and Touretzky et al. in [8].

Another solution to mitigate the impact of residential consumers on the electric grid, and consequently reliance on peaking power plants, is to implement home energy management systems (HEMSs). A HEMS shapes the residential electric load by interacting with smart appliances and scheduling their electric loads by managing start times, operation modes, etc. The term "smart appliance" refers to a broad range of appliances that can be connected to electric meters and home energy management systems that optimally manage energy usage in the home. An appliance being labeled "smart", however, does not guarantee that the device is being efficiently managed. For consumers that are focused on completion times of operations such as washing laundry or dishes, a HEMS can interact with demand response programs and reduce electricity costs by avoiding the peak costs for a TOU pricing scheme. Given enough homes responding to pricing signals, an aggregation of HEMSs can shift loads off peak times and flatten the load overall.

The utilization of HEMSs to achieve energy goals, such as lowering peak loads or reducing electricity bills, is a significant focus of energy systems research. Numerous researchers concentrate on extracting information from smart meter data, developing advanced control strategies to leverage renewable resources and, in general, creating systems whereby residential consumers become integrated participants in the smart grid. In [9], Stadler et al. considered the synergistic response of an ensemble of appliances to control signals. By aggregating the power demand of refrigerators in a community of houses, they developed two different schemes that could shift refrigerator loads. The result was that control signals could be used to create short term power reserves with delivery within $15 \mathrm{~min}$ of time. In order to reduce large loads, in [10] Steyn et al. in South Africa developed a control interface that can turn off heating and lighting systems above a household peaking threshold by monitoring smart meter data. Pipattanasomporn et al. considered a demand response program that prioritized appliance shift- 
ing according to user comfort constraints, giving a hierarchal choice in which appliances shift first [11]. In their study, they showed that the impact of user preferences will be significant for individual houses, but leveled in the aggregate given a large enough population with diverse user preferences. In [12], Xiong et al. described the implementation of an in-home power scheduler for demand-response using a home area network and considering the communication protocol for in-home appliances. They demonstrated a demand profile that was flattened using control. Jiang et al. applied demand response to minimize cost according to TOU pricing, then scheduled a fleet of combined heat and power systems and a battery system to meet the demand for a community of houses [13]. Several other studies [14]-[21] have also shown the benefits of residential energy management, including increasing grid stability and leveraging distributed generation sources.

Various other applications in demand response with appliances and HVAC systems and are summarized in [15], which reviews various current and potential demand-response programs. In summary, many existing studies have identified residential consumers as significant participants and resource in the future smart grid.

In this paper,we propose a HEMS framework that differs significantly from previous approaches. In our work, we will consider control for a community of houses in order to reduce the peak load. Rather than focusing on providing a pricing scheme that encourages users to shift energy use to off-peak times, we assume user participation in a centralized control that will seek to minimize peak demand while abiding by individual user preferences such as thermostat settings or appliance task completion times. In our approach we will consider the control of the largest loads contributing to peak power consumption: air conditioning and time-dependent domestic appliances. First, we use our previously developed technique [24] to derive simplified linear models of A/C energy use of individual consumers as a function of outdoor ambient temperature and thermostat set points using smart meter data. We use these models in a centralized model predictive control (MPC) scheme to find the set points that minimize peak energy first only considering only A/C energy use. Second, we model domestic appliance energy use with residential appliance use data and then concurrently find the optimal scheduling of appliance start times to level aggregate electricity demand for this group of homes. By identifying and controlling two large contributors to peak power demand, we discernibly flatten the overall energy use profile and reduce the peak power demand for a community of homes. 


\section{METHODOLOGY}

\subsection{Data}

Whole-house electricity consumption data, thermostat set points, and dry bulb temperatures for 40 physical houses in Austin, Texas, were provided by the Pecan Street Smart Grid Demonstration Project in 1-minute time intervals from to June 1st through June 8th, 2013 [22]. Each house was metered with an eGauge power monitor that reported whole-house power consumption in watts. The homes were equipped with smart thermostats that recorded the thermostat set point. The neighborhood consists mostly of new (since 2007), green-built houses and has a large amount of new technology penetration, such as rooftop photovoltaic panels and plug-in vehicles [22]. The houses were equipped with electric A/C cooling units and natural gas heating systems. The $\mathrm{A} / \mathrm{C}$ electricity use was disaggregated from the overall electricity profile using a technique previously reported in [23]. Appliance energy use data were modeled after typical appliance energy use profiles derived from yearly smart meter data. Appliance delayability values came from the Smart-A project, which consists of extensive surveys on residential device use times [4]. Further details are given in Section 2.3.

\subsection{A/C Energy Modeling}

In our previous work, we derived a linear autoregressive with exogenous inputs (ARX) model of electricity use from smart meter data [24]. The model estimates A/C energy usage in hourly intervals using hourly inputs of thermostat set points and dry bulb temperatures. The original form of the model comes from [25]:

$$
\begin{array}{r}
e_{A C_{i, t}=a \cdot e_{A C_{i, t-1}}}+\sum_{k=0}^{2}\left[b_{i} \cdot T_{d b t_{t-k}}+c_{i} \cdot T_{\text {thermostat }_{i, t-k}}\right] \\
+d_{i}\left[T_{d b t_{i}}\right]^{2}+f_{i} \cdot T_{d b t_{i}} \cdot T_{\text {thermostat }_{i, t}}+h_{t}
\end{array}
$$

where $e_{A C_{i, t}}$ is the $\mathrm{A} / \mathrm{C}$ electricity consumption for house $i$ at time $t, T_{d b t_{t}}$ is the outdoor dry bulb temperature at time $t, T_{\text {thermostat }_{i, t}}$ is the thermostat set point for house $i$ at time $t$, and parameters $a_{i}$ - $h_{i}$ are house-specific model coefficients. The parameter $h_{t}$ allows for a different constant term for each time period of the day, which accounts for other disturbances such as occupancy and solar irradiation. The estimated energy use values predicted by 
the model were found to align closely with the measured values [24]. This model was chosen because the inputs to the model (the house thermostat set points) and the outputs (the hourly air conditioning electricity consumption) are useful for residential A/C energy use management through thermostat control. For further information regarding the limitations and validation of the model, the reader is referred to [25].

\subsection{Appliance Energy Consumption Modeling}

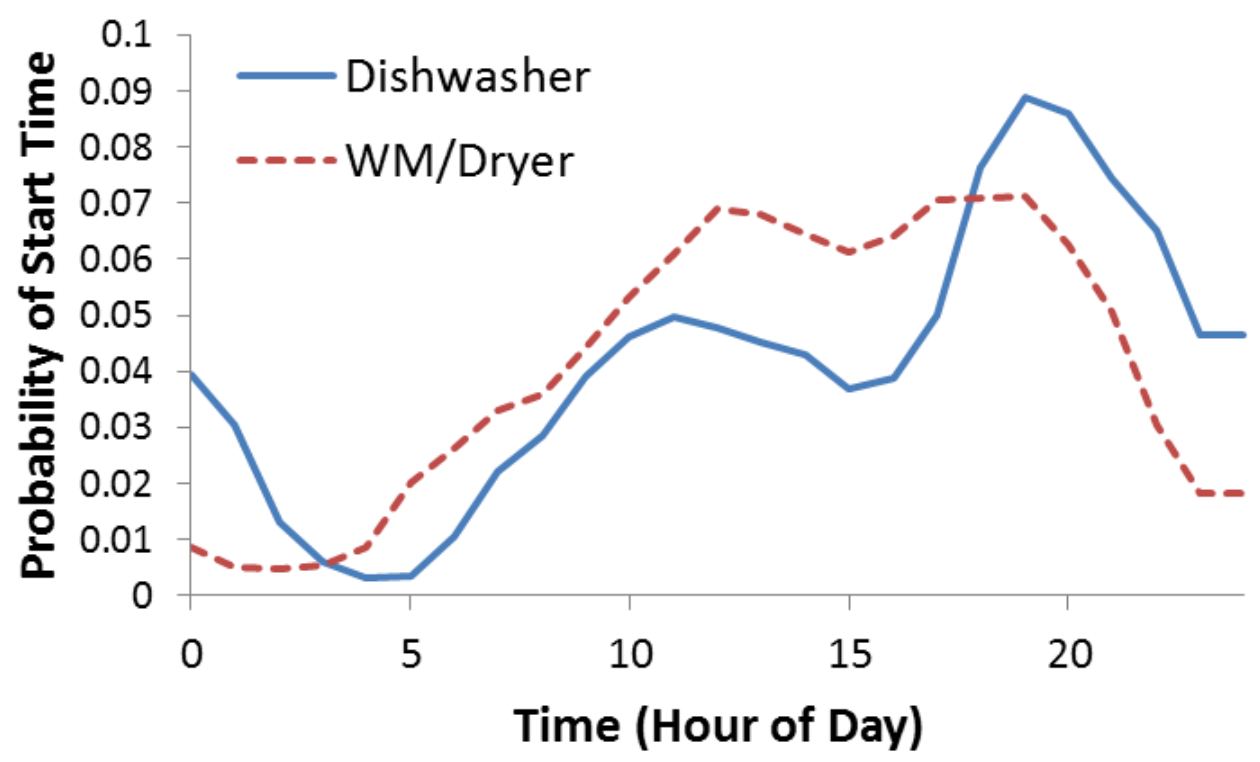

Figure 2: Probability distribution profile of start times for dishwasher and washing machine $(\mathrm{WM}) /$ dryer combination

Each house was assumed to own two time-shiftable appliances: a dishwasher and a washing machine/electric dryer combination. The probability distribution profiles of start times for the devices come from disaggregated hourly smart data of appliance use from 100 homes in 2014 from the Pecan Street Project. The start times from appliances were recorded and then quantified into a probability distribution function. The probability profile of initial startup times for each device in each house is shown in Figure 2 and is very similar to the overall Europe profile reported in a European survey of residential appliance use [4]. Because the profiles are similar, the spread 
in allowable delay times (the amount of time each device was allowed to shift) was assumed to be the same as reported in the Smart-A project. The actual energy use of each device at each operating hour is as given in the Smart-A project report and summarized in Table 1 . The survey data did not explicitly state how start times are related to permission to delay. Most washing machines are not housed in the same machine as the dryer and still require human interaction to transfer the clothing. Therefore the switching between washing and drying operation may affect the ability to delay start time. In addition, it is unclear from the survey data how often machines are run (consecutive loads or throughout the week.) In our model, each house was given a consistent start time per day to run appliances. The washer was run five times a week and the dishwasher four times a week. Dishwashers only run for one hour, while the combination washing machine/dryer runs for three hours. It was assumed that the washing machine and dryer acted as a single unit. This study does not consider customers opting out of the program, but it should be noted that according to the survey data [4], 17.5\% of the houses do not allow appliance shifting and $22.5 \%$ allow at maximum one hour of shifting.

Table 1: Appliance Energy Use in $(\mathrm{kW})$

\begin{tabular}{|l|l|l|}
\hline Hour & Washing Machine $\backslash$ Dryer & Dishwasher \\
\hline 1 & 0.775 & 0.6 \\
\hline 2 & 1.9 & N/A \\
\hline 3 & 0.635 & N/A \\
\hline
\end{tabular}

\subsection{Optimization Strategy}

Figure 3 gives an overview the optimization strategy employed. The overall strategy for the peak reduction is to implement model predictive control (MPC) on thermostats for a community of houses using the developed $\mathrm{A} / \mathrm{C}$ energy use model shown in Equation (1). A centralized control system will use MPC to minimize the peak cumulative power load for the group of houses by determining the optimal thermostat set points for each home. The main benefit of MPC in this framework is that it allows the centralized controller to take advantage of passive thermal energy storage by pre-cooling the thermal mass (structural elements) of the houses. The controller takes advantage of the differences between houses $(\mathrm{A} / \mathrm{C}$ in houses that have thinner 


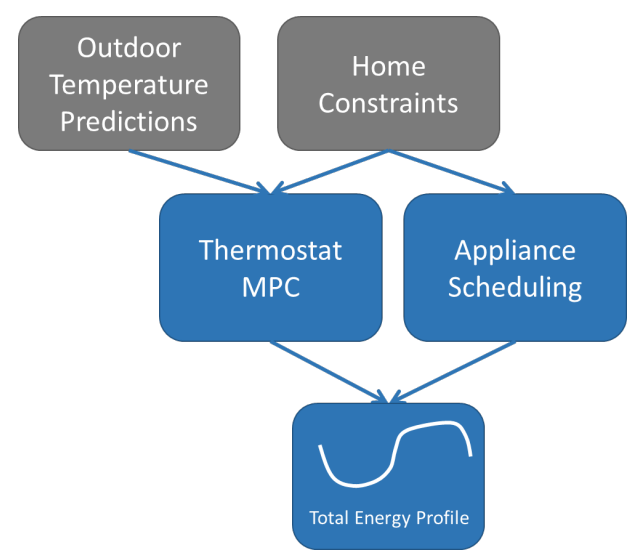

Figure 3: Overview for the optimization strategy employed. MPC of thermostat set points is followed by optimal appliance scheduling to further reduce peak loads

thermal envelopes or tight thermostat constraints can still run during peak times, while houses with large thermal envelopes are precooled and allowed to slowly warm up). In both cases the thermal comfort bounds of each house are satisfied. We describe the benefit of centralized MPC in [24]. At the same time, the schedule of the dishwasher and washing machine/dryer operation is optimized to further reduce peak load. The formulation for the overall optimization strategy is given by

$$
\begin{aligned}
& \underset{T_{\text {thermostat }_{i, t}}{\text { shour } i_{i, j, t}}_{\text {peak }}}{\min } \\
& E_{\text {peak }} \geq \sum_{i=1}^{\text {numHouses }} e_{A C_{i, t}}+e_{A P P_{i, t}} \forall t \\
& e_{A C_{i, t}}=f\left(e_{A C_{i, t-1}}, T_{\text {thermostat }_{i, t: t-2}}, T_{d b t_{i, t: t-2}}\right) \\
& 0 \leq e_{A C_{i, t}} \leq e_{A C \max _{i}} \\
& T_{l b_{i, t}} \leq T_{\text {thermostat }_{i, t}} \leq T_{u b_{i, t}} \\
& e_{A P P_{i, t}}=\sum_{j=1}^{\text {numAppliances }} s_{\text {hour } 1_{i, j, t}} * e_{\text {hour } 1}+s_{\text {hour } 2_{i, j, t}} * e_{\text {hour } 2}+s_{\text {hour } 3_{i, j, t}} * e_{\text {hour } 3}
\end{aligned}
$$




$$
\begin{aligned}
& \text { numTimesteps } \\
& \sum_{t} \quad s_{\text {hour }_{i, j, t}}=1 \quad \forall i, \forall j \\
& s_{\text {hour }_{i, j, t+1}} \geq s_{\text {hour }_{i, j, t}} \quad \forall t \\
& s_{\text {hour }_{i, j, t+2}} \geq s_{\text {hour }_{i, j, t}} \quad \forall t \\
& s_{\text {hour }_{i, j, t}}=0 \quad \forall t<t_{\text {permittedstart }},{ }_{i, j} \\
& s_{\text {hour }_{i, j, t}}=0 \quad \forall t<t_{\text {permittedstart }_{i, j}}+t_{\text {delay }_{i, j}} \\
& s_{\text {hour }_{i, j, t}}, s_{\text {hour }_{i, j, t}}, s_{\text {hour }_{i, j, t}} \in\{0,1\} \\
& T_{\text {thermostat }_{i, t}} \in \mathbb{R}
\end{aligned}
$$

$E_{\text {peak }}$ is the maximum energy use of the community of homes over the time horizon of $t=1$ to $t=1+M, i$ is the index for the houses, $t$ is the index for the time step (with 1-hour time steps) and $N$ is the total number of houses. In Equations 2 and 3 we set the conditions of the optimization to minimize the peak energy value of the community of houses while considering $\mathrm{A} / \mathrm{C}$ and appliance energy consumption.

In this scheme, the thermostat set point $\left(T_{\text {thermostat }_{i, t}}\right)$ is a manipulated variable and the air conditioning electricity consumption $\left(e_{A C_{i, t}}\right)$ is a "controlled" variable. Equation $4, f$ is the linear reduced-order model of A/C energy use described earlier in Equation 1. The outdoor dry bulb temperature $\left(T_{d b t_{i, t}}\right)$ is a disturbance variable. Weather predictions for the dry bulb temperature are assumed to be accurate. While this may seem like a strong assumption, we note that it has been shown that predictive controllers for building HVAC systems using a simple weather model can achieve results that are within 1-2\% of an optimal, perfect-prediction solution [26]. It is also assumed that occupants cannot override the set points chosen by the controller. Solving the optimization problem give results in the optimal thermostat set points $\left(T_{\text {thermostat }_{i, t}}\right)$ for each house $i$ as a function of time $t$. Note that the problem is solved sequentially, with a running 12-hour time horizon that is shifted in time by one hour at each time step. Equation 5 limits the amount 
of energy that can be drawn by the $\mathrm{A} / \mathrm{C}$ unit, where $e_{A C \max _{i}}$ is the maximum electricity consumption of the air conditioning unit of house $i$ at time $t$ (as provided by the data). The determination of the optimal thermostat set point is formulated as a MPC framework that operates over a prediction horizon $\mathrm{M}$ of 11 hours.

The upper- and lower-bound temperatures $T_{u b}$ and $T_{l b}$ of each house in Equation 6 were found by identifying the minimum and maximum thermostat set points from data. The lower bound was assumed to be the lowest allowable set point the users would accept in terms of thermal comfort. The upper bound was assigned two values depending on the time of day. From the data, it was unclear which houses were occupied during the day. Therefore, all houses were assumed to follow the same schedule. During typical workday hours (8:00-17:00) the houses were assumed to be unoccupied. The maximum set point throughout the entire data set for each individual house was set to be the maximum set point during unoccupied hours. During occupied hours, the maximum set point for each house was assumed to be the minimum set point found in the data set for each house plus $2.22{ }^{\circ} \mathrm{C}\left(4^{\circ} \mathrm{F}\right)$. For houses that had a narrower minimum and maximum set point band than $2.22{ }^{\circ} \mathrm{C}\left(4{ }^{\circ} \mathrm{F}\right)$, the minimum and maximum set points followed what was found in the data. In this way, the range of allowable set points for each house never exceeded the region where the model (Equation 1) was trained.

We formulate the flexible appliance scheduling problem as a mixed-integer linear program. The problem is embedded in the MPC problem where $e_{A P P_{i, t}}$ is the electricity used by appliances (Equation 7). In this scheme, $e_{A P P_{i, t}}$ is a function of $s_{\text {hour } 1_{i, j, t}}$, the binary variable that keeps track of the initial start time for each device. The binary variable $s_{\text {hour } 1_{i, j, t}}$ for each device and house at each hour are either 1 (appliance has turned on) or 0 otherwise. Equations 8-10 ensure the appliances run for the full time period once they have turned on. Equations 11 and 12 restrict the times when the appliances are allowed to turn on by taking into account the preferred start time $t_{\text {permittedstart }_{i, j}}$ and the permitted delay $t_{\text {delay }_{i, j}}$. Both values come from the residential survey data referred to earlier in the paper. $s_{\text {hour } 2_{i, j, t}}$ and $s_{\text {hour } 3_{i, j, t}}$ are used to track appliances which run over multiple one-hour time periods, such as the washing machine/dryer combination. $e_{A P P_{i, t}}$ is a summation of time periods when the appliances are operating (e.g. $\left.s_{\text {hour }_{i, j, t}}\right)$ multiplied by the energy consumption corresponding to the hour of operation (e.g. $\left.e_{\text {hour } 1}\right)$. 


\section{RESULTS}

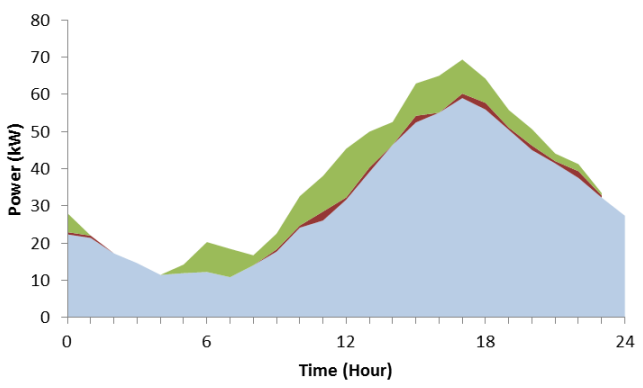

(a)

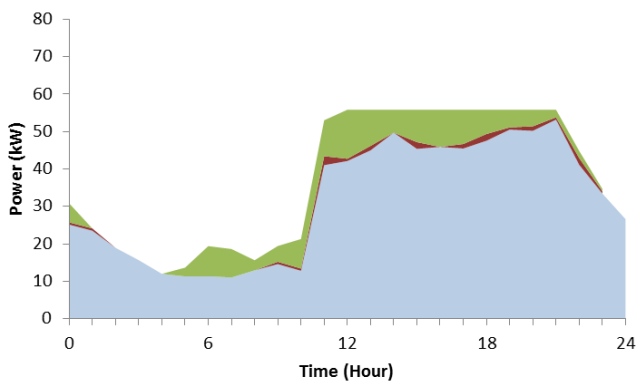

(c)

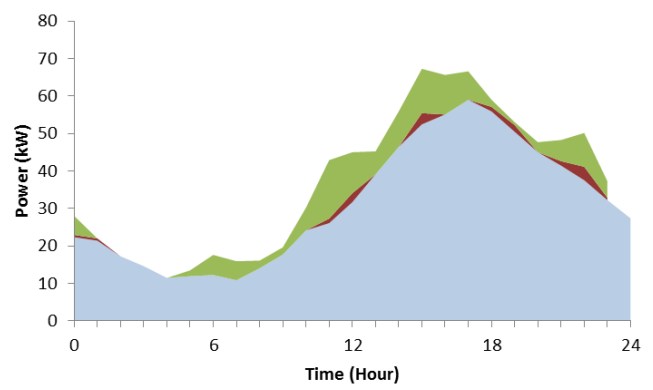

(b)

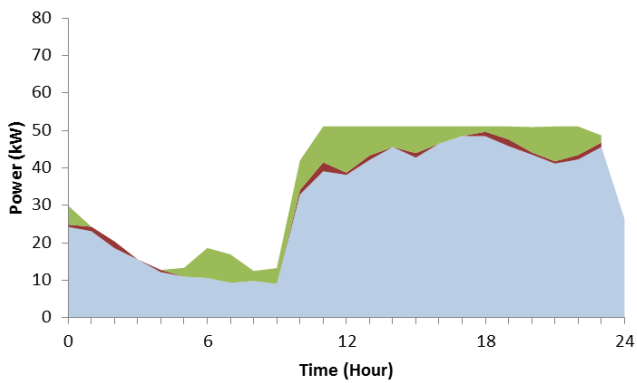

(d)

Figure 4: Electricity demand for single example day, (a) Original thermostat and original appliance start times (b) Original thermostat and optimal appliance start times (c) MPC thermostat and original appliance start times (d) MPC thermostat and optimal appliance start times

- A/C - Dishwasher - Washing Machine/Dryer

In this study, four scenarios were evaluated. In the base case, thermostat settings are the same as reported in the residential data and appliances were set to the original start times from survey data. In the second case, only appliance shifting is scheduled to minimize peak load but houses retained original thermostat set points. In the third, thermostats are controlled to lower peak load using MPC without appliance shifting. In the final case, first MPC is performed to flatten the A/C load along with optimal appliance scheduling. The optimization was formulated as a MILP and equations 2-12 were solved with GAMS v24.4.1 [27] using CPLEX v12.6.1.0 [28] in 0.02 sec. 
Figure 4 shows the results for the four evaluated cases for one day on June 1st, 2013. In the base case (Fig 4a), the A/C energy use follows the daily cyclical temperature swing and results in a peak at 5PM. The peak in appliance energy consumption is similar to the peak caused by the $\mathrm{A} / \mathrm{C}$ unit. With respect to the total load of the system, the appliances are not a very large contributor. However, in the ensemble of all appliances for this group of 40 houses appliances actually sensibly increases the size of the peak value.

Figure $4 \mathrm{~b}$ shows the results if appliance shifting is allowed. At peak times, appliance shifting reduces the load by $3.0 \%(2.1 \mathrm{~kW})$. In our optimization, we were limited to the available schedules and permitted delay. Greater reductions could come from an energy provider that incentivizes consumers to be more flexible. The contribution may also become more significant if $\mathrm{A} / \mathrm{C}$ is a less dominant load.

The advantage of pre-cooling houses is shown in Figure 4c. The centralized controller chooses to lower thermostat settings earlier in the day so that some houses are pre-cooled and thus use less energy later in the day during peak hours. Moreover, the optimal control solution entails staggering the start times of the difference $\mathrm{A} / \mathrm{C}$ units. The central controller can shift the peaks of each individual house and successfully level the overall cooling load. This operational scheme was not explicitly stated in the controller formulation. Rather, it is the result of the optimization and one of the benefits of centralized control. The reduction in peak energy use is evidenced by the flattened A/C energy profile with a peak reduction of $19.5 \%(13.5 \mathrm{~kW})$.

Figure $4 \mathrm{~d}$ shows the result of concurrent thermostat MPC and appliance scheduling. Not only is the load of the neighborhood significantly flattened, but the strategy reduces the peak power value $25.5 \%$ or $18.3 \mathrm{~kW}$, the highest for all the strategies. In addition, the optimal solution consists of staggering the times when appliances turn on. The scheme can to shift the peaks of individual houses and successfully level the overall load. This result is a benefit of HEMS: although the contribution of individual houses may be small, the aggregate contribution to the neighborhood results in a peak reduction, while not significantly increasing electricity use. Furthermore, the optimization is performed without violating thermal comfort constraints on typical household thermostat levels or allowed appliance start times.

The total energy consumption for the optimal case was $13 \mathrm{kWh}$ lower than the base case over the course of this sample day. The total appliance energy consumption is the same, but the thermostat MPC employs pre-cooling in order to flatten $\mathrm{A} / \mathrm{C}$ energy loads and so one would expect total energy use 
values in the optimal case to be larger due to energy (refrigeration) lost to the environment. However, the centralized controller operates at the thermal comfort bounds of the consumers and thus saves energy by operating near or at the boundaries. Therefore the total energy use values are very similar.

Figure 5 presents the overall plot of energy consumption for the 40 houses for the same test day. The combination of thermostat MPC and appliance shifting results in the flattest load with energy demand spread throughout the day. In comparison, without control, the $\mathrm{A} / \mathrm{C}$ units operate at less efficient thermostat settings, which results in higher peaks and overall energy consumption, and appliances operate during typical peak demand periods. In addition, control of both appliances and A/C energy use has a synergistic effect that results in a lower peak value than either strategy alone.

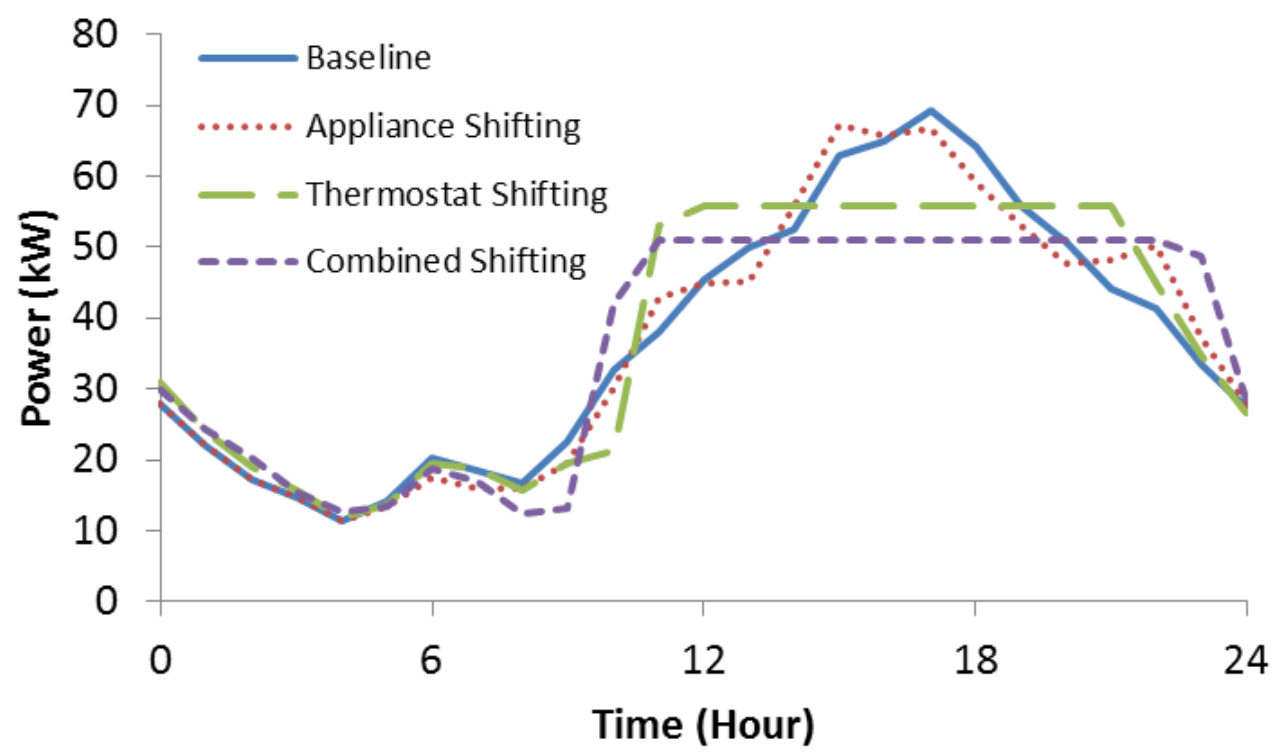

Figure 5: Overall power demand for sample day. 


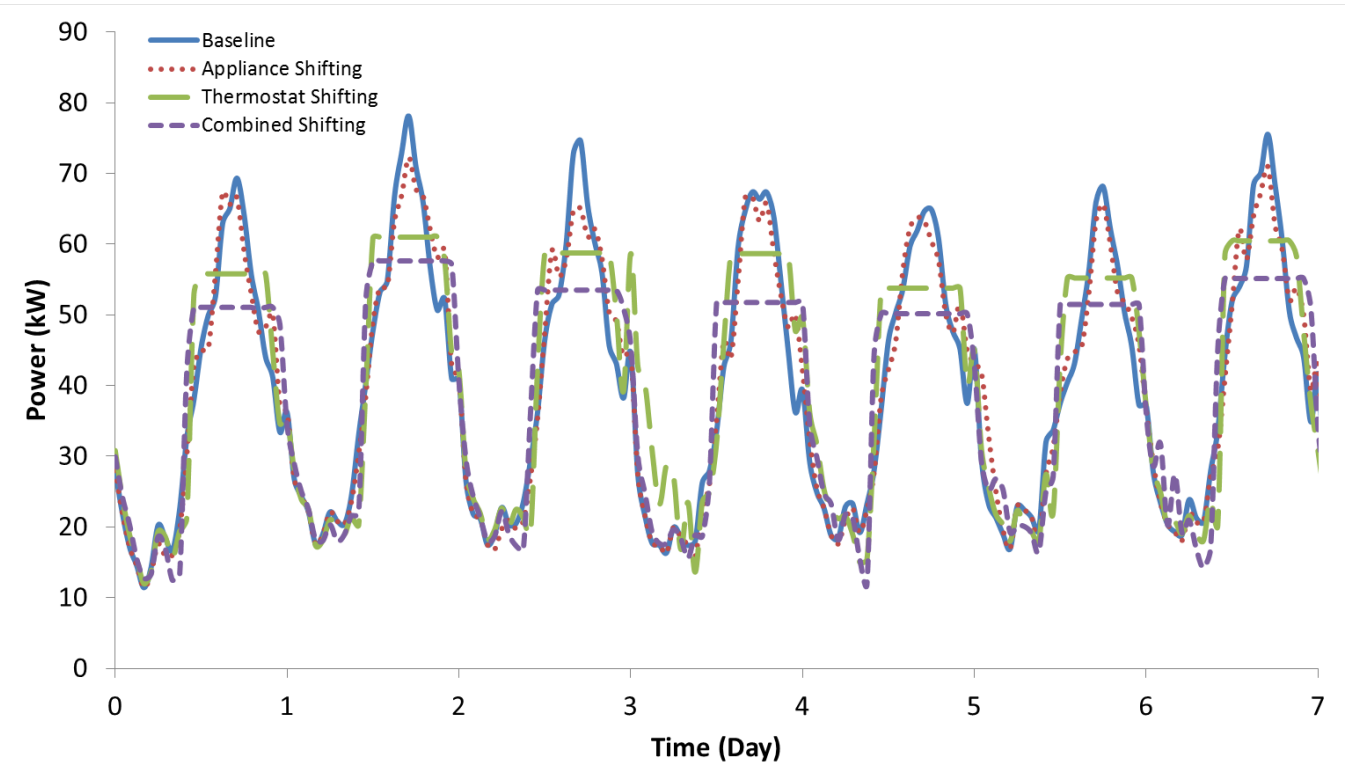

Figure 6: Overall electric power demand for test week.

Figure 6 shows the results for a full week of data while considering the impact of the thermostat MPC and appliance shifting. The combination of the two strategies results, again, in the flattest profile and the lower peak load. The centralized strategy is effective as it leverages the differences in thermostat settings, appliance use times and thermal capacities of the homes. From an electricity supplier's perspective, a strength of this results is that it is easier for the system to cope with a predictable and flattened electricity demand even if total energy use is marginally increased. A flattened profile allows an energy provider to use efficient base load plants for a longer time and reduce the need to install additional peaking capacity.

Lastly, Table 7 contains the overall results for the time period considered. Although both appliance shifting and thermostat control can lower peak load, the combination of the two has the greatest potential. The combination has an average peak reduction of $25.5 \%(18.2 \mathrm{~kW})$ for a group of 40 houses. When scaled to much larger neighborhoods, the potential for peak reduction can be substantial. Thermostat MPC has the greatest potential in savings, but these savings are dependent on ambient conditions and climate. This study evaluated a week in June, but the same total peak load reduction would not be seen during fall or winter when A/C use is lower. Overall, appliance shifting alone reduces energy consumption by about $6 \%(3.8 \mathrm{~kW})$ 
for this neighborhood of 40 houses, and these savings should scale well with the neighborhood size.

\begin{tabular}{|l|c|c|c|c|}
\cline { 2 - 5 } \multicolumn{1}{c|}{} & \multicolumn{4}{c|}{ Peak Energy } \\
\cline { 2 - 5 } \multicolumn{1}{c|}{} & Initial & \multicolumn{1}{|c|}{ App } & Thermostat & Combined \\
\hline Day 1 & 69.3 & 67.3 & 55.8 & 51.1 \\
\hline Day 2 & 78.1 & 72.3 & 61.0 & 57.6 \\
\hline Day 3 & 74.6 & 65.1 & 58.7 & 53.5 \\
\hline Day 4 & 67.4 & 66.7 & 58.6 & 51.8 \\
\hline Day 5 & 64.9 & 63.8 & 53.8 & 50.2 \\
\hline Day 6 & 68.2 & 65.7 & 55.2 & 51.5 \\
\hline Day 7 & 75.5 & 71.0 & 60.5 & 55.1 \\
\hline Average Reduction (kW) & & $\mathbf{3 . 8}$ & $\mathbf{1 3 . 5}$ & $\mathbf{1 8 . 2}$ \\
\hline Percentage Reduction & & $\mathbf{5 . 1} \%$ & $\mathbf{1 8 . 8} \%$ & $\mathbf{2 5 . 5} \%$ \\
\hline
\end{tabular}

Figure 7: Total peak energy consumption for the base case, appliance shifting, thermostat MPC and a combination of the two.

\section{CONCLUSIONS}

In this work, we assessed the ability of an optimal home energy management system to minimize peak load for a community of houses by evaluating the effect of centralized model predictive control of thermostat set-points and simultaneous optimal scheduling of appliance use start times. The system was constrained to respect the typical thermostat set points specified for occupants and preferred appliance start times. The results showed that manipulating thermostat set points alone can reduce peak loads by an average of $18.8 \%(13.5 \mathrm{~kW})$. Appliance shifting reduces the peak load 5.1\% (3.8kW) and the combination of thermostat MPC and appliance scheduling reduced peak loads by $25.5 \%(18.2 \mathrm{~kW})$. The results of this significant peak reduction correspond to weather conditions for residential consumers in Austin, TX, USA. It would be reasonable, considering that there are almost 9 million houses in Texas [29], to suggest that even a fraction of home owners participating in this type of demand response program could have a significant impact on grid operations. Other hot climates will likely see similar results. One conclusion to be drawn is that in hotter regions it may be beneficial to first focus on demand-response programs aimed at $\mathrm{A} / \mathrm{C}$ systems rather than ordinary appliances. Although control of A/C energy use was the most substantial 
contributor to peak energy use reduction in this climate, appliance-shifting may still have an important impact in colder regions.

Although this research made assumptions about the willingness of residential consumers to participate in a centralized control strategy, the results show a sizable reduction for a group of just 40 houses. However, individual consumers are not likely to contribute if they are required to make manual changes themselves, thus highlighting the need for a HEMS that will leverage the difference in preferences, behaviors and physical components in order achieve peak energy reduction in an automated way.

In our future work, we would like to expand control to consider energy storage systems and the impact of distributed generation systems. From an economic standpoint, the benefits from a residential owner's participation in this type of demand response program may be minimal. However, because electricity prices fluctuate throughout the day, it may be more economically valuable from the electricity generator's perspective to provide energy credits to consumers in exchange for participation in this type of demand response program. One avenue for research is using electricity market to quantify the relative benefit to both parties. We would also like to consider the impact of shifting loads on the efficiency of electricity generation (e.g., shifting from less efficient peaking units to more efficient combined cycle units.)

\section{ACKNOWLEDGMENTS}

This work was supported by the Pecan Street Research Institute (a 501(c)3 nonprofit public-private partnership in Austin, Texas), the United States Department of Energy, and the University of Texas at Austin. This material is also based upon work supported by the National Science Foundation Graduate Research Fellowship under Grant No. DGE-1110007. Any opinion, findings, and conclusions or recommendations expressed in this material are those of the authors and do not necessarily reflect the views of the National Science Foundation. 
j

$t$

$s_{\text {hour } 1_{i, j, t}}$

$s_{\text {hour } 2_{i, j, t}}$

$s_{\text {hour } 3_{i, j, t}}$

$E_{\text {peak }}$

$e_{A C_{i, t}}$

$e_{A P P_{i, t}}$

$e_{\text {hour } 1_{j}}$

$e_{\text {hour } 2 j}$

$e_{\text {hour } 3_{j}}$

$T_{\text {thermostat }}, t$

$T_{d b t_{i, t}}$

$T_{l b_{i, t}}$

$T_{u b_{i, t}}$

$t_{\text {permittedstart }}, j$

$t_{\text {delay }_{i, j}}$

$e_{A C \max _{i}}$ house

appliance

time (hour)

Start time index for device $\mathrm{j}$ at house $\mathrm{i}$ for hour 1 (1 for on, 0 otherwise)

Start time index for device $\mathrm{j}$ at house $\mathrm{i}$ for hour 2 ( 1 for on, 0 otherwise)

Start time index for device $\mathrm{j}$ at house $\mathrm{i}$ for hour 3 ( 1 for on, 0 otherwise)

Peak power value for community of houses $(\mathrm{kW})$

$\mathrm{A} / \mathrm{C}$ power for house $\mathrm{h}$ at time $\mathrm{t}(\mathrm{kW})$

Appliance power for house $\mathrm{h}$ at time $\mathrm{t}(\mathrm{kW})$

Power demand for appliance $\mathrm{j}$ at for first running hour $(\mathrm{kW})$

Power demand for appliance $\mathrm{j}$ at for second running hour $(\mathrm{kW})$

Power demand for appliance $\mathrm{j}$ at for third running hour $(\mathrm{kW})$

Scheduled thermostat set point for house $\mathrm{h}$ at time $\mathrm{t}\left({ }^{\circ} \mathrm{C}\right)$

Dry bulb temperature outside $\left({ }^{\circ} \mathrm{C}\right)$

Thermostat lower bound for house $\mathrm{h}$ at time $\mathrm{t}\left({ }^{\circ} \mathrm{C}\right)$

Thermostat upper bound for house $\mathrm{h}$ at time $\mathrm{t}\left({ }^{\circ} \mathrm{C}\right)$

Permitted start time for device a in house h (from survey data) (hr)

Permitted delay from original device preferences (from survey data) (hr) $a_{i}-d_{i}, f_{i}$ Model fit

Max A/C power withdraw allowed for house i $(\mathrm{kW})$

[1] H. Farhangi. The path of the smart grid. Power and Energy Magazine, IEEE, 8(1):18-28, 2010.

[2] P. Wattles. Ercot demand response overview \& status report. In AMITDSWG Workshop AMIs Next Frontier: Demand Response, 2011.

[3] L. Pérez-Lombard, J. Ortiz, and C. Pout. A review on buildings energy consumption information. Energy and buildings, 40(3):394-398, 2008.

[4] R. Stamminger, G Broil, C Pakula, H Jungbecker, M Braun, I. Rüdenauer, and C. Wendker. Synergy potential of smart appliances. Report of the SmartA project, 2008.

[5] Austin Energy. City of austin electric rate schedules. 2015. 
[6] A. Molderink, V. Bakker, M.G.C Bosman, J.L. Hurink, and G. J.M. Smit. Management and control of domestic smart grid technology. IEEE Transactions on Smart Grid, 1(2):109-119, 2010.

[7] M.E.T. Gerards, H.A. Toersche, G. Hoogsteen, T. van der Klauw, J.L. Hurink, and G.J.M. Smit. Demand side management using profile steering. In PowerTech, 2015 IEEE Eindhoven, pages 1-6. IEEE, 2015.

[8] Cara R Touretzky and Rakesh Patil. Building-level power demand forecasting framework using building specific inputs: Development and applications. Applied Energy, 147:466-477, 2015.

[9] M. Stadler, W. Krause, M. Sonnenschein, and U. Vogel. Modelling and evaluation of control schemes for enhancing load shift of electricity demand for cooling devices. Environmental Modelling \& Software, 24(2):285-295, 2009.

[10] S. Steyn and R. Chetty. Development of a residential appliance control interface (aci) module using smart systems. In Industrial Technology (ICIT), 2013 IEEE International Conference on, pages 820-825. IEEE, 2013.

[11] M. Pipattanasomporn, M. Kuzlu, and S. Rahman. An algorithm for intelligent home energy management and demand response analysis. Smart Grid, IEEE Transactions on, 3(4):2166-2173, 2012.

[12] G. Xiong, C. Chen, S. Kishore, and A. Yener. Smart (in-home) power scheduling for demand response on the smart grid. In Innovative smart grid technologies (ISGT), 2011 IEEE PES, pages 1-7. IEEE, 2011.

[13] B. Jiang and Y. Fei. Dynamic residential demand response and distributed generation management in smart microgrid with hierarchical agents. Energy Procedia, 12:76-90, 2011.

[14] C.R. Touretzky and M. Baldea. Model reduction and nonlinear mpc for energy management in buildings. In American Control Conference (ACC), 2013, pages 461-466. IEEE, 2013.

[15] F. Shariatzadeh, P. Mandal, and A. Srivastava. Demand response for sustainable energy systems: A review, application and implementation strategy. Renewable and Sustainable Energy Reviews, 45:343-350, 2015.

[16] A. Saha, M. Kuzlu, and M. Pipattanasomporn. Demonstration of a home energy management system with smart thermostat control. In Innovative Smart Grid Technologies (ISGT), 2013 IEEE PES, pages 1-8. IEEE, 2013. 
[17] X. Chen, S.H. Yang, C.B. Wong, P. Moore, and J. Chen. Domestic space heating energy control via smart home energy management. In Mechatronics and Automation (ICMA), 2015 IEEE International Conference on, pages 905-911. IEEE, 2015.

[18] A.M. Vega, F. Santamaria, and E. Rivas. Modeling for home electric energy management: A review. Renewable and Sustainable Energy Reviews, 52:948959, 2015.

[19] M.E.T. Gerards, H.A. Toersche, G. Hoogsteen, T. van der Klauw, J.L. Hurink, and G.J.M. Smit. Demand side management using profile steering. In PowerTech, 2015 IEEE Eindhoven, pages 1-6. IEEE, 2015.

[20] K.J. Kircher and K.M. Zhang. Model predictive control of thermal storage for demand response. pages 956-961, 2015.

[21] M. Rastegar, M. Fotuhi-Firuzabad, and H. Zareipour. Home energy management incorporating operational priority of appliances. International Journal of Electrical Power \& Energy Systems, 74:286-292, 2016.

[22] J.D. Rhodes, C.R. Upshaw, C.B. Harris, C.M. Meehan, D.A. Walling, P.A. Navrátil, A.L. Beck, K. Nagasawa, R.L. Fares, W.J. Cole, et al. Experimental and data collection methods for a large-scale smart grid deployment: Methods and first results. Energy, 65:462-471, 2014.

[23] K.X. Perez, W.J. Cole, J.D. Rhodes, A. Ondeck, M. Webber, M. Baldea, and T.F. Edgar. Nonintrusive disaggregation of residential air-conditioning loads from sub-hourly smart meter data. Energy and Buildings, 81:316-325, 2014.

[24] K.X. Perez, W.J. Cole, M. Baldea, and T.F. Edgar. Meters to models: Using smart meter data to predict and control home energy use. In ACEEE 2014 Summer Study on Energy Efficiency in Buildings, 2014.

[25] W.J. Cole, K.M. Powell, E.T. Hale, and T.F. Edgar. Reduced-order residential home modeling for model predictive control. Energy and Buildings, 74:69-77, 2014 .

[26] G.P. Henze, A.R. Florita, M.J. Brandemuehl, C. Felsmann, and H. Cheng. Advances in near-optimal control of passive building thermal storage. Journal of Solar Energy Engineering, 132(2):021009, 2010.

[27] R.E. Rosenthal. GAMS-a user's guide. GAMS Development Corporation, Washington, DC, 2014. 
471 [28] CPLEX. http://www.gams.com/dd/docs/solvers/cplex.pdf, last retrieved $472 \quad 8 / 3 / 2014$.

473 [29] U.S. Census Bureau. Texas quickfacts. 2015. 